\title{
Perancangan Kendali Optimal pada Motor Arus Searah Tanpa Sikat melalui Metode LQRI
}

\author{
KHOIRUDIN FATHONI, ARYO BASKORO UTOMO
}

\author{
Jurusan Teknik Elektro, Universitas Negeri Semarang \\ Email : khoirudinfathoni@mail.unnes.ac.id
}

Received 10 Desember 2018 | Revised 4 Februari 2019 | Accepted 20 April 2019

\begin{abstract}
ABSTRAK
Artikel ini akan menjelaskan perancangan kendali kecepatan MASTS dengan tujuan diperoleh respon kecepatan MASTS yang tanggap serta memiliki sinyal kendali dan arus minimal. Untuk mencapai hal ini MASTS akan dikendalikan melalui metode Linear Quadratic Regulator (LQR) dengan state yang dipilih adalah arus, kecepatan, dan state integral galat kecepatan. Diperlukan penalaan nilai parameter $Q$ matriks bobot state dan $R$ matriks bobot input untuk mendapatkan performa kecepatan dan arus yang terbaik. Berdasarkan pengujian diperoleh bahwa dengan kendali LQR-I, kecepatan MASTS dapat mengikuti set point dengan respon rise time $\mathrm{Tr}=0,03$ detik, settling time $T_{s}=0,044$ detik, overshoot (OS) $1,6 \%$, arus $I_{\max }=0,16 \mathrm{~A}$ dan dutycycle sinyal kontrol $u_{\max } 56 \%$ pada kondisi tanpa beban dan $\mathrm{Tr}=0,03$ detik, $T_{s}=0,044$ detik, OS 1,6\%, $I_{\max }=0,16 \mathrm{~A}$ dan $u_{\max } 56 \%$ pada kondisi berbeban. Dibandingkan dengan kendali PID ketika tanpa beban mempunyai $T_{r}=0,0176 T_{s}=0,075 \% 0 S=3,9 \% u_{\max }=96 \%$ $I_{\max }=0,35 \mathrm{~A}, L Q R I$ mempunyai respon settling time, sinyal kendali dan arus yang lebih baik.
\end{abstract}

Kata kunci: Motor Arus Searah Tanpa Sikat, Kendali Optimal, Linear Quadratic Regulator dan Integral

\begin{abstract}
This paper aimed to discuss further research about BLDC motor speed control so that BLDC not only has fast speed response but also has minimum control signal and current using LQR (Linear Quadratic Regulator) control with chosen states are current, speed of BLDC, and speed error integral state. Tuning of $Q$ and $R$ matrix is required to reach the best speed and current performance. Where $Q$ and $R$ matrix is state cost matrix and input cost matrix, respectively. Result show that $L Q R-I$ control can track set point with rise time $\mathrm{Tr}=0.03 \mathrm{~s}$, settling time $T s=0,044 s$, overshoot (OS) $1,6 \%$, current $I_{\max }=0,16 \mathrm{~A}$ and dutycycle control signal $u_{\max } 56 \%$ in no load condition, and $\mathrm{Tr}=0,03 \mathrm{~s}, \mathrm{Ts}=0,044 \mathrm{~s}$, OS 1,6\%, $I_{\max }=0,16 \mathrm{~A}$ dan $u_{\max } 56 \%$ in the load condition. Compared to PID controller which has $\mathrm{Tr}=0,0176 \mathrm{Ts}=0,075 \% 0 \mathrm{~S}=3,9 \%$ umax $=96 \%$ Imax $=0,35 \mathrm{~A}$ in no load condition, proposed controller has a better settling time, control signal and current.
\end{abstract}

Keywords: BLDC Motor, Optimal Control, LQR and Integral 


\section{PENDAHULUAN}

Penggunaan Motor DC sebagai penggerak telah umum digunakan dalam berbagai macam perangkat karena relatif mudah diatur kecepatan putarnya (Morales, Somolinos, \& Siraramírez, 2014). Namun motor DC konvensional ini mempunyai kelemahan yaitu adanya sikat sebagai komutator mekanik untuk mengatur arah arus, yang semakin lama dapat aus dan rusak sehingga perlu diganti secara berkala (Riba, López-torres, Romeral, \& Garcia, 2016). Komutasi mekanik dengan sikat ini mulai digantikan dengan komutasi elektronik pada Motor Brushless DC (BLDC) atau Motor Arus Searah Tanpa Sikat (MASTS) sehingga MASTS akan mempunyai kecepatan dan efisiensi yang lebih baik.

MASTS pada umumnya mempunyai konstruksi motor sinkron berbentuk tiga fasa dengan magnet permanen. MASTS memerlukan arus bolak-balik pada stator untuk dapat bergerak (Bertoluzzo, Buja, Fellow, Keshri, \& Menis, 2015). Sehingga meskipun bernama motor arus searah, MASTS tidak dapat bekerja langsung pada arus searah namun diperlukan saklar elektronik sebagai komutator untuk membalik arah arus stator, dimana penskalaran tersebut berdasarkan posisi rotor yang dapat diketahui melalui sensor maupun tanpa sensor. Untuk yang bersensor umumnya menggunakan sensor hall efek dan encoder sementara tanpa sensor melalui umpan balik tegangan EMF balik, ataupun fungsi kecepatan flux (Chen, Liu, \& Zhu, 2017).

Salah satu aspek penting pada kendali motor adalah dalam pengendalian kecepatan putarnya. Pada pengendalian kecepatan MASTS dengan sensor hall efek, akan muncul dua permasalahan yaitu bagaimana mengatur inverter melalui pentiga fasa sesuai pembacaan kondisi sensor hall efek agar motor dapat berputar dan bagaimana pengaturan kecepatan motor itu sendiri agar dapat mengikuti set point yang diinginkan. Pada permasalahan pertama secara spesifik penggunaan saklar tiga fasa menggunakan saklar elektronis misalnya Field Effect Transistor (FET) membutuhkan pembatasan arus untuk mencegah kerusakan. Terlebih pada kondisi transien dan kondisi pembebanan. Pada masalah pengendalian kecepatan MASTS, kecepatan di sini adalah kecepatan sudut/putar MASTS yang bisa dinyatakan dalam rad/detik atau rpm, diperlukan metode pengendalian agar MASTS mencapai set point kecepatan yang diinginkan dengan respon transien yang cepat serta batasan arus dan sinyal kontrol yang optimal. Sehingga diperlukan skema untuk mengendalikan MASTS agar tercapai kecepatan yang diinginkan dengan arus dan sinyal kontrol yang optimal. Penelitian terkait pengendalian MASTS telah dilakukan. Penelitian yang dilakukan oleh Tibor dan timnya (Tibor, Fedak, \& Durovský, 2011) serta Poovizhi dan timnya (Poovizhi, Senthil Kumaran, Ragul, \& Irene Priyadarshini, 2017) dibuat model simulasi MASTS pada MATLAB, untuk Tibor, simulasi dibentuk dalam GUI agar nilai parameter MASTS dapat diubah. Namun keduanya belum membahas kendali kecepatannya. Penelitian oleh Saputra dan timnya (Saputra et al., 2012) MASTS digunakan pada robot empat roda dengan pengendalian kecepatan masih secara on-off control. Penelitian oleh Xu dan timnya (Ling Xu, Jian-Guo Song, \& Qiang-Qiang Lin, 2016) serta Varatharaju (Varatharaju, Mathur, \& Udhyakumar, 2010) mensimulasikan MASTS dan pengendaliannya menggunakan kendali double loop PI (Proportional Integral) dengan umpan balik kecepatan dan arus. Sementara penelitian oleh Ardiansyah (Ardiansyah, 2017) menerapkan kendali Proportional Integral Derivative (PID) untuk pengendalian posisi sudut MASTS, sedangkan penelitian oleh Istiananda dan timnya (Istiananda, Fachrudin, Effendie, \& Ashfahani, 2016) serta Marimuthu dan Rajaiah (Marimuthu \& Rajaiah, 2016) kendali PID masing-masing dikombinasikan dengan robust control dan Linear Quadratic Regulator (LQR). Pada penelitian Ardiansyah, parameter PID masih dicari melalui trial and error. Sementara pada penelitian Istiananda, model yang digunakan dalam 
perancangan diperoleh melalui identifikasi sistem yang berbeda-beda tergantung beban yang diberikan ke motor dengan best fit maksimal 79\%. Model yang berubah ini akan dapat mengubah parameter kendali PID-robust yang telah dirancang. Kendali logika fuzzy digunakan pada penelitian Shanmugasundram dan timnya (Shanmugasundram, Zakariah, \& Yadaiah, 2014) serta Yulianta dan timnya (Yulianta, Hadi, \& Suharyanto, 2015) untuk pengaturan kecepatan MASTS. Keduanya membandingkan respon MASTS dengan kendali PID. Namun pada penelitian Yulianta, tidak melakukan pengujian kendali dengan beban. Sedangkan pada peneltian Shanmugasundram, telah dilakukan pengujian dengan beban namun tidak melihat arus dan sinyal kontrol yang dibutuhkan. Kendali LQR pada penelitian Francis (Francis, 2015), serta Mekha dan timnya (Mekha \& Aswin, 2016) dan Marimuthu state yang dipilih bukan arus dan kecepatan, namun dengan model state space MASTS diperoleh dari pengubahan dari fungsi alih orde-2 dengan pendekatan model motor dc konvensional sehingga model menjadi kurang tepat serta state yang dipilih tidak dapat diketahui. Selain itu pengujian dengan beban juga tidak dilakukan.

Penelitian lebih lanjut diperlukan untuk mengatasi masalah di atas dengan tujuan untuk memodelkan dan merancang pengendali kecepatan MASTS dengan kendali LQR agar MASTS mampu mengikuti set point kecepatan yang diinginkan dengan respon transien yang cepat, overshoot di bawah 2\%, sinyal kontrol melalui Pulse Width Modulation (PWM)di bawah 90\% dan arus di bawah $1 \mathrm{~A}$. Dipilih kendali LQR karena LQR merupakan kendali optimal yang dapat mencari sinyal kontrol yang meminimalkan fungsi biaya (cost function). Pada teori Kendali Optimal, fungsi biaya ini terdiri dari state vector $x$ dan vektor sinyal kontrol $u$. Pada kasus MASTS ini fungsi biaya akan minimal jika dipilih arus fasa sebagai state vector dan tegangan fasa sebagai vektor sinyal kontrol. Artinya jika fungsi biaya tersebut dapat diminimalkan maka arus berlebih dan tegangan kontrol yang terlalu besar dapat dihindari. Performansi sistem kendali LQR akan diuji untuk mengikuti set point kecepatan tertentu dengan dilihat respon transiennya serta dengan uji pembebanan mendadak. Untuk mengatasi galat kondisi tunak pada saat diberi beban, akan ditambahkan state integrator untuk mengatasi hal ini.

\section{METODOLOGI}

\section{A. Pemodelan Motor Arus Searah Tanpa Sikat}

Model MASTS dapat dipisah menjadi dua bagian yaitu model elektrik dan model mekanik. Model elektrik MASTS terlihat pada Gambar 1.

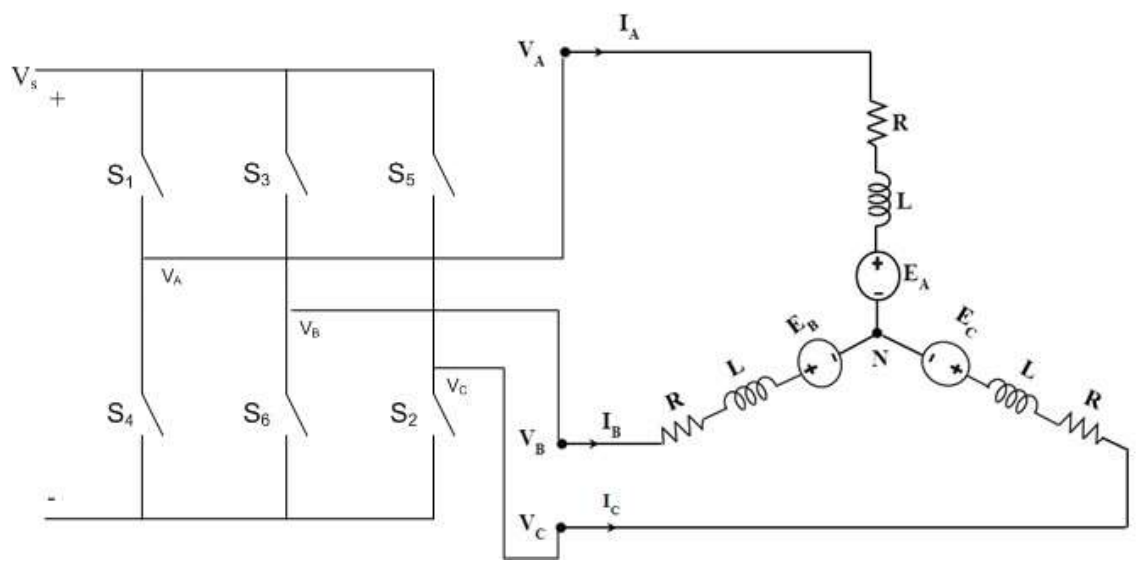

Gambar 1. Model Elektrik dan Pensaklaran MASTS 3 Fasa 
Berdasarkan Gambar 1 dapat diturunkan persamaan tegangan $V_{A}, V_{B}, V_{c}$ sebagai berikut:

$$
\begin{aligned}
& V_{A}(t)=R_{A} I_{A}(t)+L_{A} \frac{d I_{A}(t)}{d t}+E_{A}(t) \\
& V_{B}(t)=R_{B} I_{B}(t)+L_{B} \frac{d I_{B}(t)}{d t}+E_{B}(t) \\
& V_{C}(t)=R_{C} I_{C}(t)+L_{C} \frac{d I_{C}(t)}{d t}+E_{C}(t)
\end{aligned}
$$

Atau dalam bentuk Transformasi Laplace, persamaan arus $I_{A}, I_{B}, I_{C}$ dari Persamaan (1), (2), (3) adalah:

$$
\begin{aligned}
& I_{A}=\frac{V_{A}-E_{A}}{R_{A}+L_{A} s} \\
& I_{B}=\frac{V_{B}-E_{B}}{R_{B}+L_{B} s} \\
& I_{C}=\frac{V_{C}-E_{C}}{R_{C}+L_{C} s}
\end{aligned}
$$

Dengan $E_{A}, E_{B}, E_{C}$ adalah tegangan BEMF untuk masing-masing fasa pada MASTS berbentuk trapesium dapat dirumuskan sebagai:

$$
\begin{aligned}
& E_{A}=\omega_{m} K_{e} f_{a}\left(\theta_{e}\right) \\
& E_{B}=\omega_{m} K_{e} f_{b}\left(\theta_{e}\right) \\
& E_{C}=\omega_{m} K_{e} f_{c}\left(\theta_{e}\right)
\end{aligned}
$$

$\omega_{m}$ kecepatan sudut MASTS (rad/detik), $K_{e}$ konstanta EMF, $\theta_{e}$ sudut elektrik MASTS (radian) dan $f_{a}, f_{b}, f_{c}$ adalah fungsi trapezoidal untuk masing masing fasa. Hubungan antara sudut elektrik, tegangan fasa yang diberikan dan fungsi trapesium back EMF berdasarkan posisi sudut elektrik rotor terlihat pada Tabel 1.

Karena $\omega_{m}$ adalah kecepatan sudut mekanik sehingga besarnya juga dipengaruhi oleh jumlah kutub magnet rotor $p$. Sehingga hubungan antara kecepatan sudut elektrik motor $\omega_{e}$ dan kecepatan sudut mekanik motor $\omega_{m}$ adalah:

$$
\omega_{m}=\frac{2}{p} \omega_{e}
$$

Berikutnya model mekanik MASTS adalah:

$$
T_{e}-T_{L}=J \frac{2}{p} \frac{d \omega_{e}(t)}{d t}+B \frac{2}{p} \omega_{e}(t)
$$

Dengan $T_{L}$ adalah torsi beban (ketika motor diberi beban), $J$ adalah momen inersia motor, dan $B$ adalah koefisien gesekan, $p$ jumlah kutub motor. Sementara $T_{e}$ adalah torsi motor, dimana 


$$
T_{e}=\frac{P_{e}}{\omega_{e}}=\frac{E_{A} I_{A}+E_{B} I_{B}+E_{C} I_{C}}{\omega_{e}}
$$

Jika $K_{T}$ (konstanta torsi $)=K_{e}($ konstanta back EMF) maka:

$$
T_{e}=K_{T} I_{A}+K_{T} I_{B}+K_{T} I_{C}
$$

Sehingga $\omega$ dalam Laplace adalah:

$$
\begin{gathered}
T_{e}-T_{L}=\frac{2}{p} J \omega s+\frac{2}{p} B \omega \\
\omega=\frac{p\left(T_{e}-T_{L}\right)}{2\left(J_{S}+B\right)}
\end{gathered}
$$

\begin{tabular}{|c|c|c|c|c|c|}
\hline \multirow{2}{*}{$\begin{array}{c}\text { Sudut } \\
\text { Elektrik }\left(\theta_{e}\right)\end{array}$} & \multicolumn{3}{|c|}{ Tegangan } & \multirow{2}{*}{ Hall } & \multirow{2}{*}{$\begin{array}{l}\text { Fungsi trapesium } \\
\text { back EMF }\end{array}$} \\
\hline & Va & Vb & Vc & & \\
\hline $0^{0}-60^{0}$ & + & - & $\mathrm{n}$ & 110 & $\begin{array}{c}f_{a}=1 \\
f_{a}=\frac{1}{60} \theta_{e}-1 \\
f_{c}=-\frac{1}{60} \theta_{e}\end{array}$ \\
\hline $60^{\circ}-120^{\circ}$ & + & $\mathrm{n}$ & - & 010 & $\begin{array}{c}f_{a}=-\frac{1}{60} \theta_{e}+2 \\
f_{a}=\frac{1}{60} \theta_{e}-1 \\
f_{c}=-1\end{array}$ \\
\hline $120^{\circ}-180^{\circ}$ & $\mathrm{N}$ & + & - & 011 & $\begin{array}{c}f_{a}=-\frac{1}{60} \theta_{e}+2 \\
f_{b}=1 \\
f_{c}=\frac{1}{60} \theta_{e}-3\end{array}$ \\
\hline $180^{\circ}-240^{\circ}$ & - & + & $n$ & 001 & $\begin{array}{c}f_{a}=-1 \\
f_{b}=1 \\
f_{c}=\frac{1}{60} \theta_{e}-3\end{array}$ \\
\hline $240^{\circ}-300^{\circ}$ & - & $\mathrm{n}$ & + & 101 & $\begin{array}{c}f_{a}=\frac{1}{60} \theta_{e}-5 \\
f_{b}=-\frac{1}{60} \theta_{e}+4 \\
f_{c}=1\end{array}$ \\
\hline $300^{\circ}-360^{0}$ & $\mathrm{~N}$ & - & + & 100 & $\begin{array}{c}f_{a}=\frac{1}{60} \theta_{e}-5 \\
f_{b}=-1 \\
f_{c}=-\frac{1}{60} \theta_{e}+6\end{array}$ \\
\hline
\end{tabular}

Sudut mekanik motor perlu direset kembali ke nol ketika motor telah berputar satu putaran penuh yang digunakan untuk menentukan nilai sensor hall dan fungsi trapesium backemf.

Tabel 1. Hubungan Sudut Elektrik, Tegangan Fasa, Sensor Hall dan BEMF Trapesium 
Persamaan tegangan fasa melalui pensaklaran inverter sesuai dengan kondisi sensor hall efek berdasarkan Tabel 1 dimana $S_{1}-S_{6}$ bernilai 0 atau 1 supaya MASTS dapat berputar adalah:

$$
\begin{aligned}
& V_{A}=\left(S_{1}-S_{4}\right) \frac{V_{s}}{2} \\
& V_{B}=\left(S_{3}-S_{6}\right) \frac{V_{s}}{2} \\
& V_{C}=\left(S_{5}-S_{2}\right) \frac{V_{s}}{2}
\end{aligned}
$$

Blok diagram model MASTS terlihat pada Gambar 2.

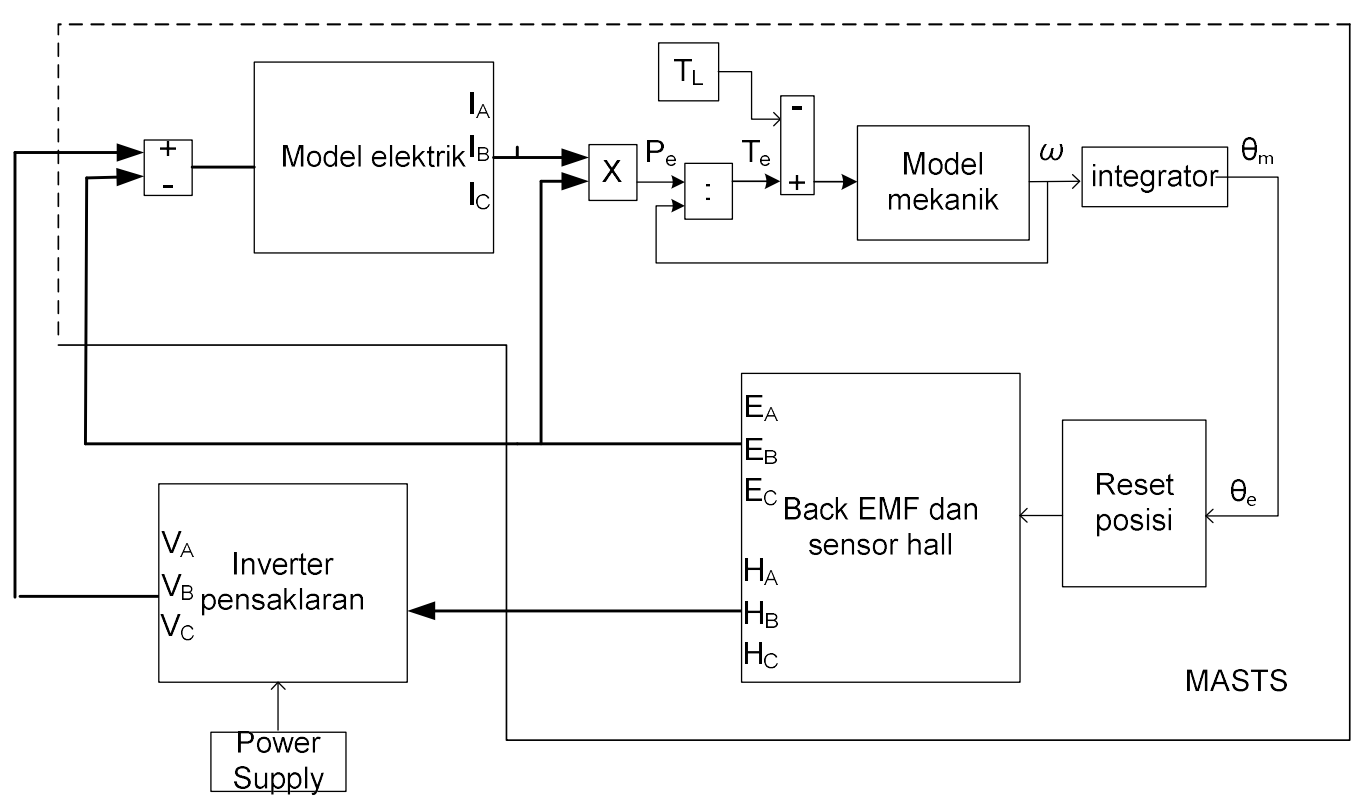

Gambar 1. Blok Diagram MASTS

Tabel 2. Parameter MASTS

\begin{tabular}{|l|l|l|}
\hline \multicolumn{1}{|c|}{ Parameter } & Simbol & \multicolumn{1}{c|}{ Nilai } \\
\hline Resistansi lilitan stator & $R$ & $13 \Omega$ \\
\hline Induktansi lilitan stator & $L$ & $0,6 \mathrm{mH}$ \\
\hline Inersia motor & $J$ & $56 \times 10^{-6} \mathrm{Kg} \cdot \mathrm{m}^{2}$ \\
\hline Koefisien gesek & $B$ & $1 \times 10^{-5} \mathrm{~N} /(\mathrm{rad} / \mathrm{s})$ \\
\hline Jumlah kutub magnet & $P$ & 4 \\
\hline Konstanta BEMF & $K_{e}$ & $0,15 \mathrm{~V} /(\mathrm{rad} / \mathrm{s})$ \\
\hline Konstanta torsi & $K_{T}$ & $0,15 \mathrm{~N} \cdot \mathrm{m} / \mathrm{A}$ \\
\hline Torsi beban maks & $T_{L}$ & $0,3 \mathrm{~N} \cdot \mathrm{m}$ \\
\hline Tegangan sumber & $V_{S}$ & $48 \mathrm{~V}$
\end{tabular}


Parameter MASTS yang digunakan dapat dilihat pada Tabel 2, dengan $R_{a}=R_{b}=R_{C}=R$ dan $L_{a}=L_{b}=L_{c}=L$.

Kemudian model ini diubah menjadi bentuk ruang keadaan/ state space Persamaan (19) dengan state yang dipilih adalah arus fasa $I_{a}, I_{b}, I_{c}$ dan $\omega$ dari Persamaan (1)- Persamaan (3), Persamaan (11), Persamaan (13) input adalah $V_{A, B, C}$ dan $T_{L}$ sedangkan output $y$ adalah $\omega:$

$$
\begin{aligned}
& \dot{x}(t)=A x(t)+B u(t) \\
& y(t)=C x(t)+D u(t) \\
& \left(\begin{array}{c}
\dot{I}_{A} \\
\dot{I}_{B} \\
\dot{I}_{C} \\
\dot{\omega}
\end{array}\right)=\left(\begin{array}{cccc}
-\frac{R}{L} & 0 & 0 & -\frac{K_{e}}{L} \\
0 & -\frac{R}{L} & 0 & -\frac{K_{e}}{L} \\
0 & 0 & -\frac{R}{L} & -\frac{K_{e}}{L} \\
\frac{2 K_{T}}{J} & \frac{2 K_{T}}{J} & \frac{2 K_{T}}{J} & -\frac{2 B}{J}
\end{array}\right)\left(\begin{array}{c}
I_{A} \\
I_{B} \\
I_{C} \\
\omega
\end{array}\right)+\left(\begin{array}{cccc}
\frac{1}{L} & 0 & 0 & 0 \\
0 & \frac{1}{L} & 0 & 0 \\
0 & 0 & \frac{1}{L} & 0 \\
0 & 0 & 0 & -\frac{2}{J}
\end{array}\right)\left(\begin{array}{l}
V_{A} \\
V_{B} \\
V_{C} \\
T_{L}
\end{array}\right) \\
& y=\left(\begin{array}{llll}
0 & 0 & 0 & 1
\end{array}\right)\left(\begin{array}{c}
I_{A} \\
I_{B} \\
I_{C} \\
\omega
\end{array}\right)
\end{aligned}
$$

Model state space pada Persamaan (17) dan (18) ini yang akan digunakan untuk merancang kendali LQR.

\section{B. Perancangan Kendali LQR-I}

Langkah-langkah dilakukan dalam penelitian ini adalah, pertama melakukan pemodelan MASTS secara lengkap pada Simulink MATLAB sebagaimana telah dirinci pada bab 2 sesuai Gambar 2. Kedua sebelum dilakukan kendali dengan state feedback LQR secara closed loop, dilakukan pengujian MASTS secara openloop untuk melihat performa awal MASTS sebelum diberi LQR. Pengaturan tegangan fasa dilakukan melalui Pulse Width Modulation (PWM) yang mengatur dutycycle keluaran pensaklaran tiga fasa dengan cara sinyal PWM dari pembangkit PWM dioperasikan logika AND dengan tegangan fasa keluaran inverter. Ketiga setelah diketahui performa awal MASTS open loop terutama arus dan kecepatan maksimalnya, maka dirancang pengendalian closed loop melalui LQR dengan model state space yang diperoleh pada Persamaan (17) dan Persamaan (18).

LQR adalah sistem kendali state feedback linier yang bertujuan untuk mencari sinyal kendali yang seminimal mungkin dengan cara meminimukan fungsi biaya (cost function) kuadratik J, dengan J adalah

$$
J=\int\left(x^{T} Q x+u^{T} R u\right) d t
$$

Dimana $x^{T} Q x$ adalah state cost dengan matriks bobot $\mathrm{Q} \geq 0, u^{T} R u$ adalah control cost dengan matriks bobot $\mathrm{R}>0$. Jadi tujuan dari kendali LQR adalah mencari nilai control input $u$ yang akan meminimumkan Persamaan (22). Pada kendali state feedback biasa, nilai sinyal kontrol $u$ adalah $u=-K x$. Sementara pada LQR, nilai penguatan statefedback $K$ dinyatakan dengan $K_{\text {lqr }}$ yang mana dicari melalui penyelesaian persamaan aljabar Riccati. Pada kasus 
tanpa setpoint, atau regulator, blok diagram kendali state feedback dapat dilihat pada Gambar 3.

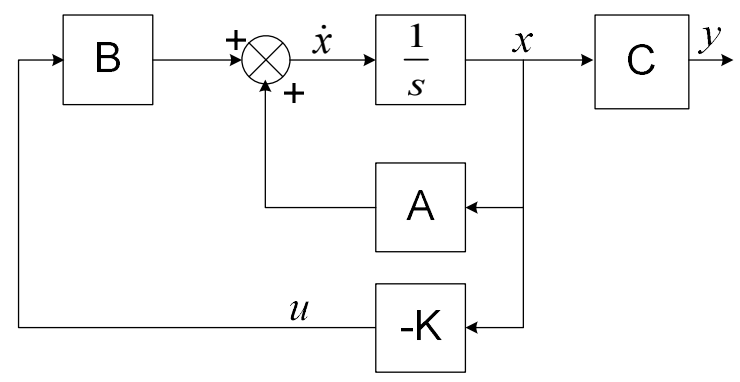

\section{Gambar 2. Blok Diagram Kendali State feedback}

Sementara pada kasus tracking setpoint, sebagaimana pada sistem kendali MASTS ini, sinyal kendali $u$ tersebut tidak dapat langsung digunakan karena akan ada galat pada kondisi tunak. Untuk mengatasi hal ini ditambahkan integral galat sebagai state kelima $\left(x_{i}\right)$. sehingga sinyal kontrol $u$ yang baru adalah $u=-K\left[X X_{i}\right]$ dengan blok diagram sebagaimana Gambar 4 .

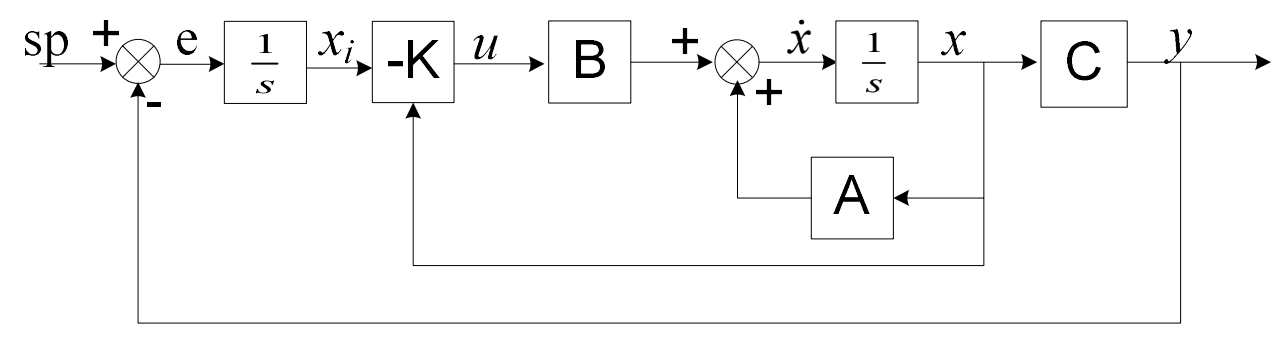

Gambar 3. Blok Diagram Kendali State feedback dengan Integral

Sinyal kontrol $u=\left[\begin{array}{llll}V_{A} & V_{B,} & V_{C}, T_{L}\end{array}\right]^{T}$ optimal akan dipengaruhi pembobotan matriks $\mathrm{Q}$ dan $\mathrm{R}$ dengan batasan-batasan state dan input yang diinginkan yaitu arus fasa maksimal, kecepatan maksimal, torsi beban maksimal, sehingga dapat meninimumkan fungsi biaya Persamaan (22).

Berdasarkan aturan Bryson (Bryson, 1994) nilai matriks $Q$ dan $R$ untuk kendali MASTS dengan integral galat ini adalah:

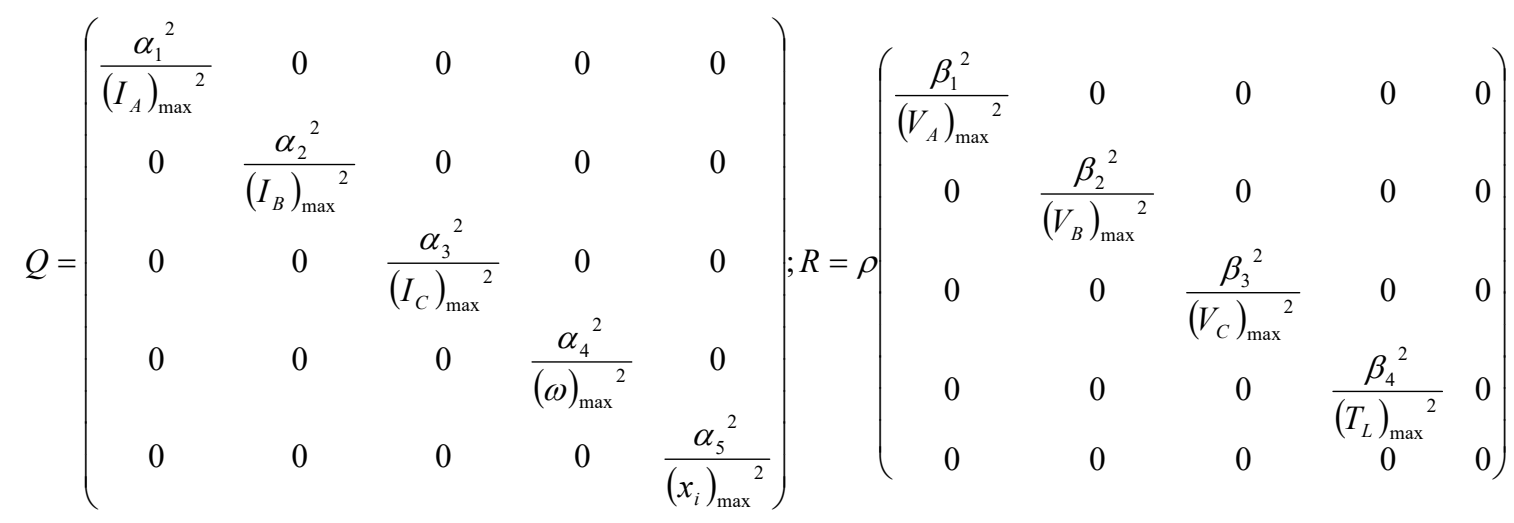

Dimana $\sum_{i} \alpha_{i}^{2}=1$ dan $\sum_{i} \beta_{i}^{2}=1$ digunakan untuk menambah pembobotan state dan input. $\left(I_{a}\right)_{\text {max }}\left(I_{b}\right)_{\text {max }}\left(I_{c}\right)_{\max }$ merepresentasikan arus maksimum yang diperbolehkan, $\omega_{\max }$ adalah kecepatan maksimum yang dapat dicapai motor, $x_{i}$ integral galat maksimum yang diinginkan. 
Sementara $\left(V_{A}\right)_{\max }\left(V_{B}\right)_{\max }\left(V_{C}\right)_{\max }$ sama dengan tegangan $V_{S_{I}}\left(T_{L}\right)_{\max }$ adalah torsi beban maksimum dan $\rho$ adalah pembobotan yang dapat ditala. Variabel state $\omega_{\max }$ dapat ditentukan saat kondisi open loop sementara $\left(I_{A}\right)_{\max }\left(I_{B}\right)_{\max }\left(I_{C}\right)_{\max }$ dengan diambil dari spesifikasi arus maksimum IGBT. Variabel input $\left(V_{A}\right)_{\max }\left(V_{B}\right)_{\max }\left(V_{C}\right)_{\max }$ diketahui dari catu daya motor, $\left(T_{L}\right)_{\max }$ dapat ditentukan dari pembebanan yang dapat diberikan ke motor saat open loop. Variabel yang belum dapat ditentukan adalah $x_{i}$ dan $\rho$ yang akan ditala nilainya dan disesuaikan dengan performa MASTS yang diinginkan. Setelah semua parameter diketahui, menggunakan MATLAB dapat dihitung nilai gain state feedback $\mathrm{K}$ yang akan digunakan sesuai blok diagram Gambar 4.

Keempat, gabungkan kendali LQR-I yang dirancang ke blok diagram open loop MASTS menjadi blok diagram Gambar 5 dengan output LQR adalah sinyal kontrol yang akan menjadi dutycycle. Kelima akan dilakukan uji dan analisis system kontrol untuk perubahan bobot matriks Q dan R untuk memperoleh performa kecepatan MASTS yang paling baik serta diuji juga untuk pemberian beban mendadak serta akan dibandingkan performanya dengan kontrol PID melalui penalaan.

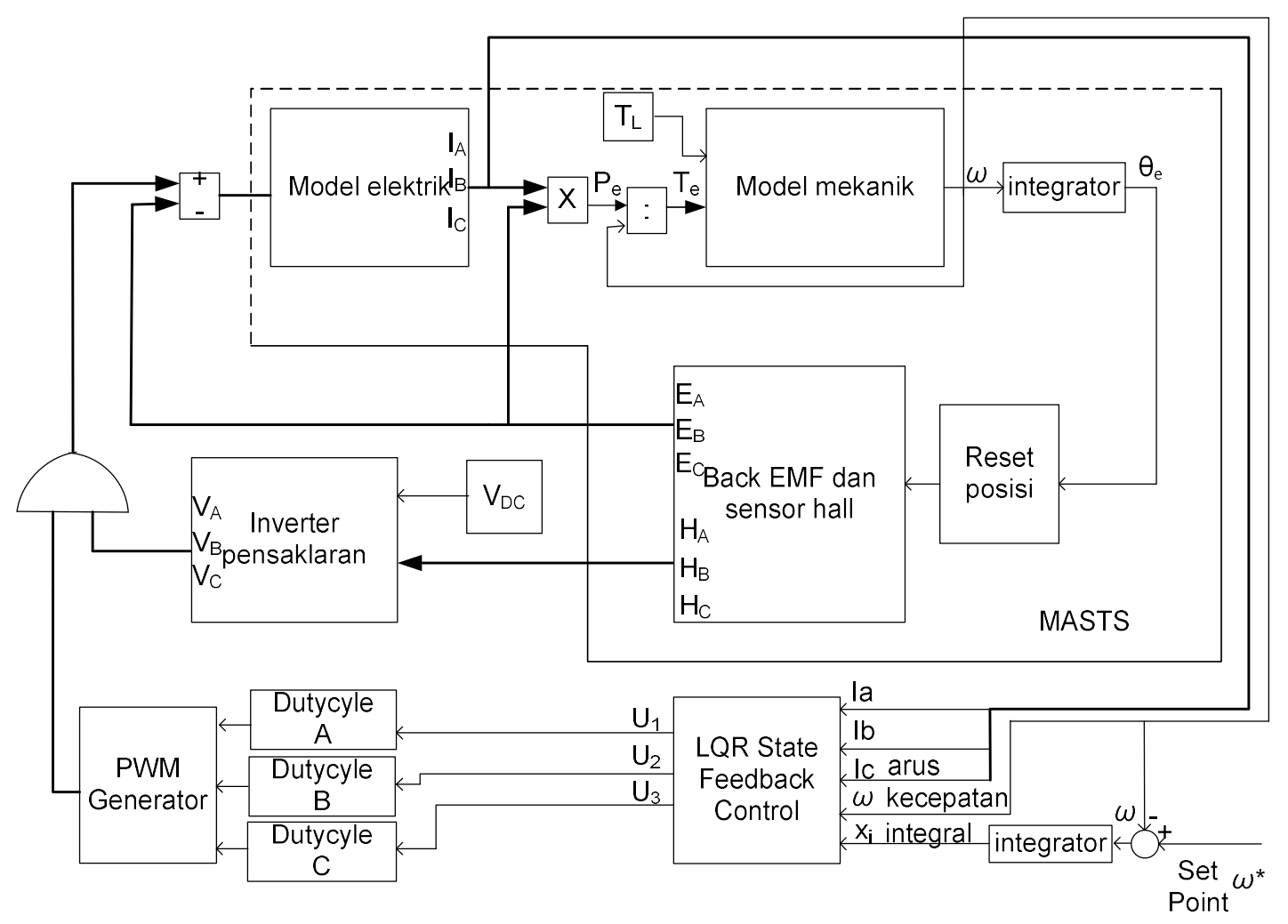

Gambar 4. Blok Diagram Kendali Closedloop MASTS dengan LQR dan Integral

\section{HASIL DAN PEMBAHASAN}

Blok diagram kendali LQR dengan Integral MASTS terlihat pada Gambar 5. Nilai dutycycle dari pembangkit PWM diubah menjadi rentang 0-1 yang menyatakan dutycycle PWM 0$100 \%$. Untuk menentukan $\left(I_{a}, I_{b}, I_{c}, \omega\right)_{\max }$ diperoleh saat dutycycle PWM $100 \%$ dengan memberi beban torsi maksimum $T_{L \max }=0,3 \mathrm{Nm}$. Karena resistansi dan induktansi tiap fasa sama maka output arus $I_{a}=I_{b}=I_{c}$ dengan $I_{\max }=1,5 \mathrm{~A}$. Output kecepatan MASTS dengan respon kecepatan $\omega_{\max }=145 \mathrm{rad} /$ detik, rise time $(T r)=0,023$ detik, settling time $( \pm 2 \%)(T s)$ 
$=0,04$ detik dan tanpa overshoot. Respon kecepatan, arus dan sinyal BEMF dan torsi MASTS dapat dilihat pada Gambar 6.

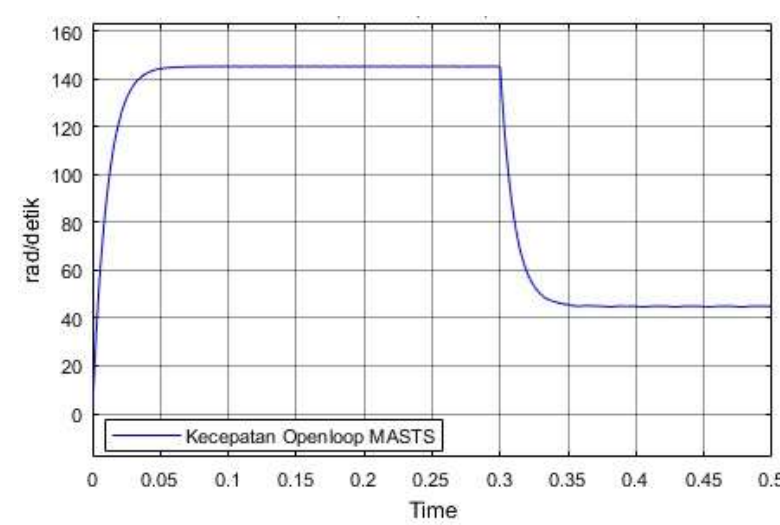

(a)

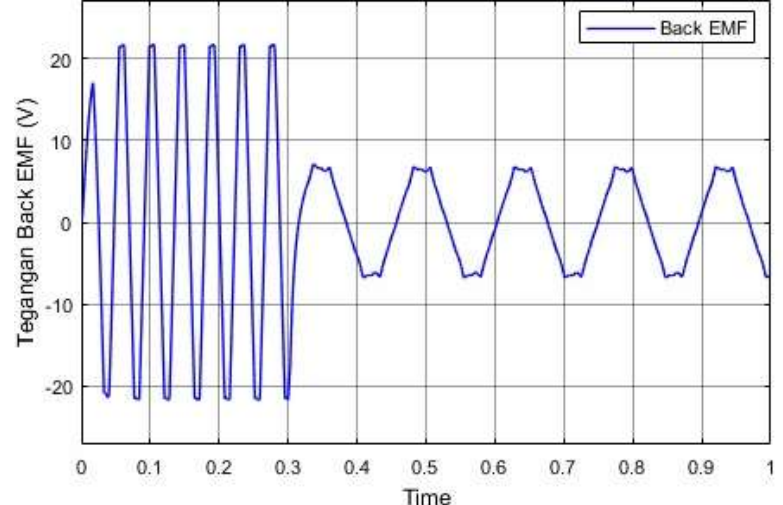

(b)

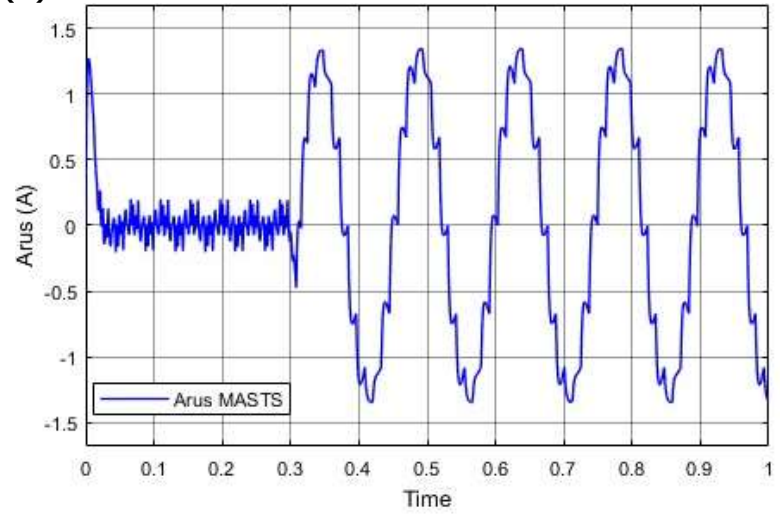

(c)

Gambar 5. Respon Awal Kecepatan (a), Back EMF (b) dan Arus MASTS (c) Diberi Beban

Kendali closed loop LQR dengan integrator terlihat pada Gambar 5, dengan parameter Q dan $\mathrm{R}$ yang dipilih berdasarkan Persamaan (23),

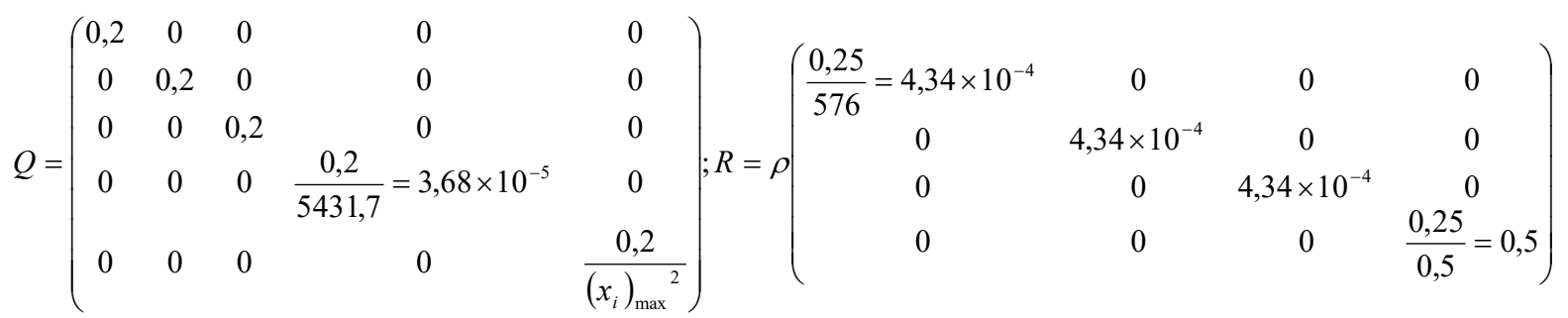

Tabel 3. Performa Kendali LQRI Pada Perubahan $\rho$

\begin{tabular}{|c|c|c|c|c|c|}
\hline \multicolumn{2}{|c|}{ Kondisi dan Respon MASTS } & $\begin{aligned} \mathrm{x}_{\mathrm{i}} & =0,05 \\
\rho & =1\end{aligned}$ & $\begin{array}{c}\mathrm{x}_{\mathrm{i}}=0,05 \\
\rho=10\end{array}$ & $\begin{array}{l}x_{i}=0,05 \\
\rho=100\end{array}$ & $\begin{array}{c}\mathrm{X}_{\mathrm{i}}=0,05 \\
\rho=1000\end{array}$ \\
\hline \multirow{5}{*}{ Tanpa beban } & $\mathrm{T}_{\mathrm{r}}$ (detik) & 0,0063 & 0,011 & 0,023 & 0,04 \\
\hline & $\mathrm{T}_{\mathrm{s}}$ (detik) & 0,037 & 0,051 & 0,059 & 0,063 \\
\hline & $\% \mathrm{OS}$ & $25,4 \%$ & $13,3 \%$ & $4,3 \%$ & 0 \\
\hline & $U_{\max }$ (duty $\left.\max \right)$ & 0,45 & 0,314 & 0,228 & 0,205 \\
\hline & $\operatorname{Imax}(A)$ & 0,6 & 0,45 & 0,23 & 0,15 \\
\hline \multirow{4}{*}{ Diberi beban } & $\mathrm{T}_{\mathrm{s}}$ (detik) & 0,0255 & 0,0345 & 0,04 & 0,1 \\
\hline & $\% O S$ & $4 \%$ & $2,6 \%$ & $0 \%$ & $0 \%$ \\
\hline & $U_{\max }($ dutymax) & 0,446 & 0,345 & 0,328 & 0,32 \\
\hline & $I_{\max }(A)$ & 0,63 & 0,42 & 0,37 & 0,35 \\
\hline
\end{tabular}


Nilai $\left(x_{i}\right)_{\max }$ dan $\rho$ akan menentukan performa MASTS. Pada set point sinyal step 30 $\mathrm{rad} /$ detik, jika mula-mula dibuat $\left(x_{i}\right)_{\max }{ }^{2}=0,01$, respon kecepatan, arus dan sinyal kontrol LQR dapat dilihat pada masing-masing Gambar 7(a) dan 7(b) ntuk beberapa nilai $\rho$ sesuai Tabel 3 dengan $\mathrm{T}_{\mathrm{r}}, \mathrm{T}_{\mathrm{s}}, \% \mathrm{OS}, \mathrm{U}_{\max }$ dan $\mathrm{I}_{\max }$ masing-masing adalah rise time, settling time $( \pm 2 \%)$, \%overshoot, sinyal kendali/dutycycle maksimum, dan arus maksimum.

Berdasarkan Tabel 3 dan Gambar 7.b dapat ditunjukkan bahwa untuk mendapatkan sinyal kontrol/dutycycle yang kecil $<30 \%$ dan stabil (tidak berosilasi) diperlukan nilai $\rho$ yang lebih besar yaitu pada $\rho=100$ dan $\rho=1000$ yang menyebabkan respon kecepatan mempunyai $\% O S$ yang kecil $<5 \%$ terlihat pada Gambar 7 (a) (garis jingga dan biru) pada kondisi tanpa beban. Hal ini karena $\rho$ berhubungan dengan nilai matriks pembobotan sinyal kontrol $\mathrm{R}$ yaitu jika $\rho$ kecil maka $R$ kecil. Agar fungsi biaya J Persamaan (22) tetap kecil ketika R diperkecil, maka sinyal kontrol/dutycycle $u$ harus diperbesar sehingga dapat menyebabkan respon transien yang overshoot tinggi dan berosilasi. Oleh karena itu akan dipilih $\rho=100$ atau $\rho$ $=1000$ yang akan dibandingkan dengan perubahan $x_{i}$ berdasarkan Tabel 4 .

Tabel 4. Performa Kendali LQRI Pada Perubahan $x_{i}$

\begin{tabular}{|c|c|c|c|c|c|}
\hline \multicolumn{2}{|c|}{ Kondisi dan Respon MASTS } & \multirow{2}{*}{$\begin{array}{l}x_{i}=\mathbf{0 , 0 5} \\
\rho=100 \\
0,023\end{array}$} & \multirow{2}{*}{$\begin{array}{l}\mathbf{x}_{\mathbf{i}}=\mathbf{0 , 1} \\
\boldsymbol{\rho}=\mathbf{1 0 0} \\
0,041\end{array}$} & \multirow{2}{*}{$\begin{array}{l}x_{\mathrm{i}}=\mathbf{0 , 0 2} \\
\rho=\mathbf{1 0 0 0} \\
0,03\end{array}$} & \multirow{2}{*}{$\begin{array}{l}\mathbf{x}_{\mathbf{i}}=\mathbf{0 , 0 1} \\
\boldsymbol{\rho}=\mathbf{1 0 0 0} \\
0,016\end{array}$} \\
\hline \multirow{5}{*}{ Tanpa beban } & $\mathrm{T}_{\mathrm{r}}$ (detik) & & & & \\
\hline & $\mathrm{T}_{\mathrm{s}}$ (detik) & 0,06 & 0,067 & 0,045 & 0,05 \\
\hline & $\% O S$ & $4,2 \%$ & $0,6 \%$ & $1,6 \%$ & $7,9 \%$ \\
\hline & $U_{\max }$ & 0,23 & 0,21 & 0,214 & 0,255 \\
\hline & $I_{\max }(A)$ & 0,22 & 0,14 & 0,16 & 0,28 \\
\hline \multirow{4}{*}{ Diberi beban } & $\mathrm{T}_{\mathrm{s}}$ (detik) & 0,041 & 0,0745 & 0,052 & 0,03 \\
\hline & $\%$ OS & $0,9 \%$ & $0 \%$ & $0,1 \%$ & $1,8 \%$ \\
\hline & $U_{\max }$ (duty $\max$ ) & 0,328 & 0,322 & 0,325 & 0,335 \\
\hline & $\operatorname{Imax}(A)$ & 0,37 & 0,352 & 0,358 & 0,36 \\
\hline
\end{tabular}

Berdasarkan Tabel 4 dan Gambar 8(a) respon yang cepat, \%OS dan sinyal kendali yang kecil terdapat pada $\mathrm{xi}=0,02 \rho=1000$ yang mempunyai $T_{s}$ paling cepat $(0,045$ detik), sinyal kendali dan arus yang optimal ( $\mathrm{u}<30 \%$ dan $\mathrm{I}<1 \mathrm{~A}$ ) sehingga dapat dipilih sebagai parameter yang tepat. Untuk $\rho$ yang sama, jika $x_{i}$ diperkecil menjadi 0,01 maka akan menghasilkan $\% O S$, sinyal kontrol dan arus yang tinggi karena $x_{i}$ berkaitan dengan nilai integral galat yang diperbolehkan. Jika $x_{i}$ kecil artinya sistem kontrol hanya mentoleransi galat yang kecil sehingga ingin sesegera mungkin untuk menghilangkan galat tersebut dengan sinyal kontrol yang besar. Hal ini dapat mengakibatkan lonjakan \%OS yang lebih besar dapat dilihat pada Gambar 8(a) dan sinyal kontrol u juga besar (Gambar 8(b) garis ungu dan biru).

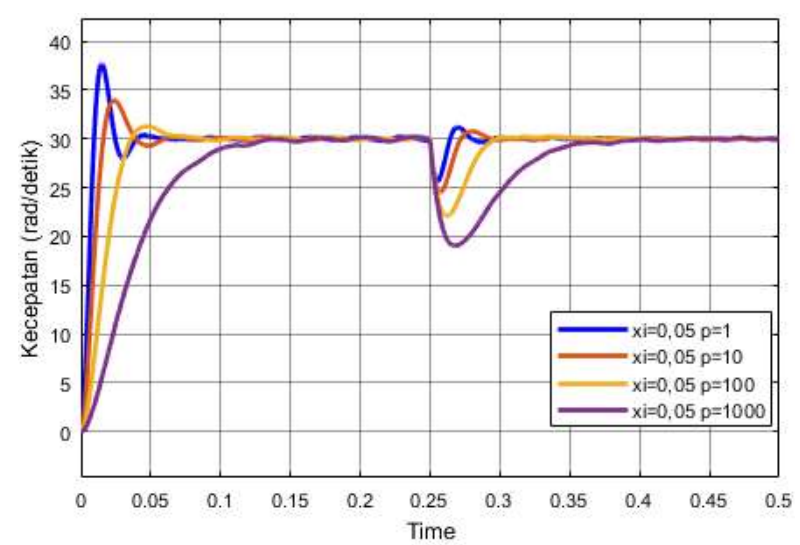

(a)

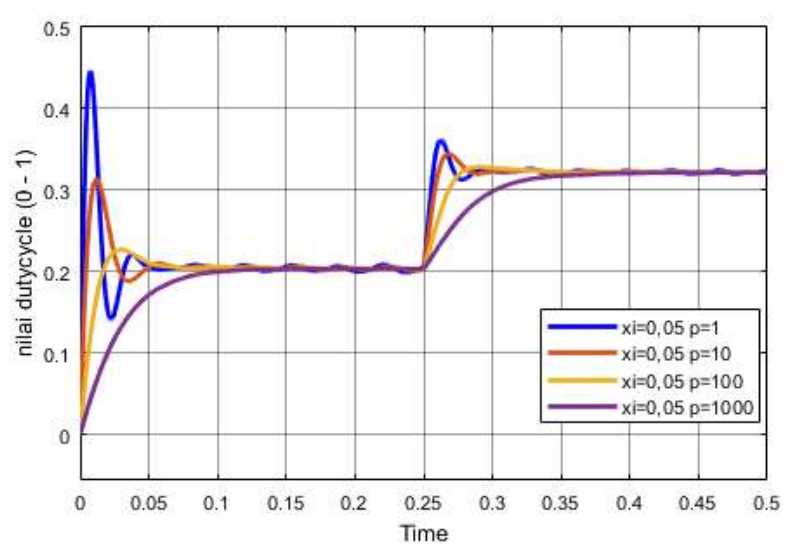

(b)

Gambar 6. Respon MASTS (a) dan sinyal kendali LQR-I (b) pada perubahan $\rho$ 


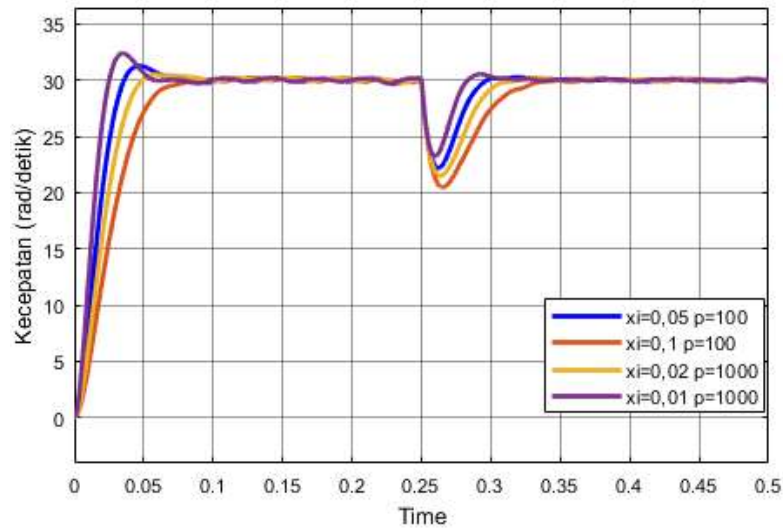

(a)

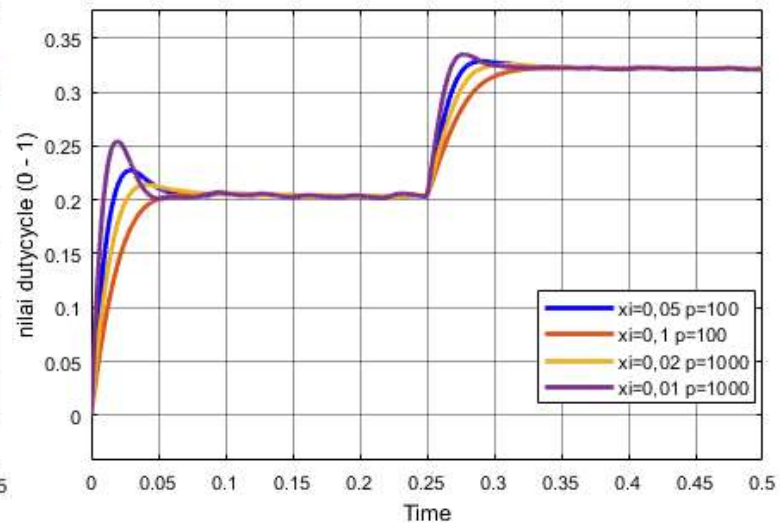

(b)

Gambar 7. Respon MASTS (a) dan sinyal kendali (b) LQR-I pada perubahan $x_{i}$

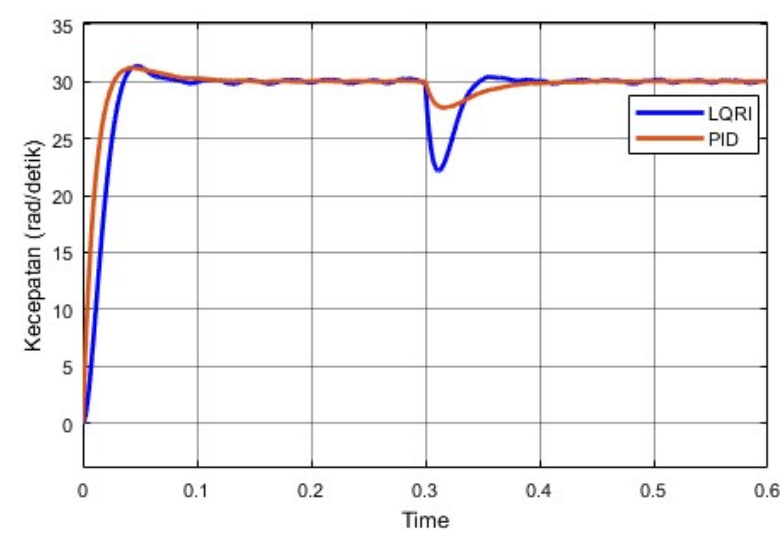

(a)

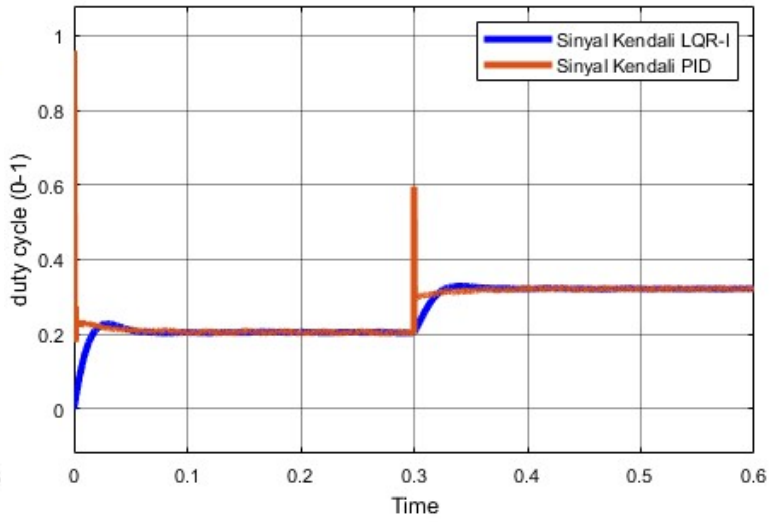

(b)

Gambar 8. Perbandingan respon MASTS antara kendali LQR-I dan kendali PID

Tabel 5. Perbandingan Kendali LQR-I dengan PID

\begin{tabular}{|l|l|l|l|}
\hline \multicolumn{2}{|l|}{ Kondisi dan Respon MASTS } & LQR-I & \multicolumn{1}{|c|}{ PID } \\
\hline \multirow{4}{*}{ Tanpa beban } & $\mathrm{T}_{\mathrm{r}}$ (detik) & 0,03 & 0,0176 \\
\cline { 2 - 4 } & $\mathrm{T}_{\mathrm{s}}$ (detik) & 0,045 & 0,075 \\
\cline { 2 - 4 } & $\% \mathrm{OS}$ & $1,6 \%$ & $3,9 \%$ \\
\cline { 2 - 4 } & $\mathrm{U}_{\max }($ dutymax $)$ & 0,214 & 0,96 \\
\cline { 2 - 4 } & $\mathrm{I}_{\max }(\mathrm{A})$ & 0,16 & 0,35 \\
\hline \multirow{4}{*}{ Diberi beban } & $\mathrm{T}_{\mathrm{s}}$ (detik) & 0,052 & 0,07 \\
\cline { 2 - 4 } & $\% \mathrm{OS}$ & $0,1 \%$ & 0 \\
\cline { 2 - 4 } & $\mathrm{U}_{\max }($ duty $\max )$ & 0,325 & 0,6 \\
\cline { 2 - 4 } & $\mathrm{I}_{\max }(\mathrm{A})$ & 0,358 & 0,37 \\
\hline
\end{tabular}

Dapat dilihat juga pada Tabel 5, jika dibandingkan dengan kendali PID dengan parameter PID melalui penalaan pada penelitian Waluyo dan timnya (Waluyo, Fitriansyah, \& Syahrial, 2013) dengan $\mathrm{Kp}=0,032, \mathrm{Ti}=0,03, \mathrm{Td}=0,0075$, kendali $\mathrm{LQR}-\mathrm{I}$ dengan $\mathrm{x}_{\mathrm{i}}=0,02$ dan $\rho=1000$, meskipun mempunyai respon $T_{r}$ yang lebih lambat namun $\% O S$ dan $T_{s}$ yang lebih baik Gambar 9(a) dengan sinyal kontrol yang lebih kecil terlihat pada Gambar 9(b) Hal ini karena kontrol PID merupakan kontrol output feedback hanya fokus kepada kecepatan tidak melihat seberapa besar sinyal kontrol maupun arus yang dibutuhkan. Sementara LQR-I merupakan kontrol state feedback yang memperhatikan state dan output sekaligus. Sehingga jika diingikan sinyal kontrol dan arus yang optimal, LQR-I merupakan pilihan yang 
tepat. Dapat dilihat juga bahwa kendali yang dirancang lebih baik dibandingkan dengan kendali LQR dengan state error Pada Francis dan Mekha karena tidak dilakukan kontrol closedloop pada MASTS serta tidak diuji dengan beban.

\section{KESIMPULAN}

Telah dirancang pemodelan dan pengendalian kecepatan Motor Arus Searah Tanpa Sikat melalui kendali optimal LQR dengan integral. Pada kendali LQR diperlukan penalaan nilai parameter $\mathrm{Q}$ dan $\mathrm{R}$ yang tepat untuk menentukan performanya. Diperlukan kompromi dalam penentuan parameter tersebut agar tercapai kondisi respon transien yang cukup cepat namun dengan sinyal kendali khususnya dutycycle tidak lebih dari $100 \%$, dan arus yang tidak terlalu besar. Berdasarkan data dan analisis, maka dapat disimpulkan bahwa perancang kendali LQR-I mampu membuat MASTS mengikuti set point kecepatan putar yang diinginkan dengan sinyal kontrol dan arus yang optimal dengan rise time $\mathrm{Tr}=0,03$ detik, settling time $T s=0,044$ detik, \%OS $1,6 \%$, arus $I_{\max }=0,16 \mathrm{~A}$ dan dutycycle sinyal kontrol $u_{\max } 56 \%$ pada kondisi tanpa beban dan $T_{r}=0,03$ detik, $T_{s}=0,044$ detik, $\%$ OS 1,6\%, $I_{\max }=0,16$ A dan $u_{\max }$ $56 \%$ pada kondisi berbeban.

\section{DAFTAR RUJUKAN}

Ardiansyah, R. A. (2017). Perancangan dan Pengujian Sistem Pengendali Sudut untuk Motor DC Brushless Menggunakan Kendali Algoritma P-D. Jurnal Rekayasa Elektrika, 13(2), 82-86. https://doi.org/10.17529/jre.v13i2.7149

Bertoluzzo, M., Buja, G., Fellow, L., Keshri, R. K., \& Menis, R. (2015). Sinusoidal vs . SquareWave Current Supply of PM Brushless DC Drives: a Convenience Analysis. IEEE Transactions on Industrial Electronics, 0046(c), 7339-7349. https://doi.org/10.1109/TIE.2015.2455518

Bryson, A. E. (1994). Control of Spacecraft and Aircraft. Princeton, NJ, USA: Princeton University.

Chen, S., Liu, G., \& Zhu, L. (2017). Sensorless Control Strategy of a 315 kW High-Speed BLDC Motor Based on a Speed-Independent Flux Linkage Function. IEEE Transactions on Industrial Electronics, 64(11), 8607-8617. https://doi.org/10.1109/TIE.2017.2698373

Francis, R. M. (2015). Speed Control of BLDC Motor using a Tuned LQR Controller, (Icettas), $1-6$.

Gamazo-Real, J. C., Vázquez-Sánchez, E., \& Gómez-Gil, J. (2010). Position and speed control of brushless dc motors using sensorless techniques and application trends. Sensors, 107), 6901-6947. https://doi.org/10.3390/s100706901

Istiananda, Fachrudin, A., Effendie, R., \& Ashfahani, A. (2016). Perancangan dan Implementasi Sistem Pengaturan Kecepatan Motor Arus Searah Tanpa Sikat Menggunakan Metode PID- Robust. Teknik ITS, 5(2), 1-7. 
Ling Xu, Jian-Guo Song, \& Qiang-Qiang Lin. (2016). Brushless DC motor speed control system Simulink simulation. 2016 IEEE International Conference on Power and Renewable Energy (ICPRE), 62-66. https://doi.org/10.1109/ICPRE.2016.7871173

Marimuthu, M., \& Rajaiah, J. (2016). An Optimal Control Theory Based Analysis of Brushless DC Motor Drive. Circuits and Systems, 7. 3384-3391.

Mekha, M. L., \& Aswin, R. B. (2016). LQR based Speed Control of BLDC Motors. SSRG International Journal of Electrical and Electronics Engineering, 3(6), 7-11.

Morales, R., Somolinos, J. A., \& Sira-ramírez, H. (2014). Control of a DC motor using algebraic derivative estimation with real time experiments. MEASUREMENT, 47, 401417. https://doi.org/10.1016/j.measurement.2013.09.024

Poovizhi, M., Senthil Kumaran, M., Ragul, P., \& Irene Priyadarshini, L. (2017). Investigation of mathematical modelling of brushless dc motor(BLDC) drives by using matlabsimulink. In 2017 International Conference on Power and Embedded Drive Control (ICPEDC).

Riba, J., López-torres, C., Romeral, L., \& Garcia, A. (2016). Rare-earth-free propulsion motors for electric vehicles: A technology review. Renewable and Sustainable Energy Reviews, 57, 367-379. https://doi.org/10.1016/j.rser.2015.12.121

Saputra, R. P., Adriansyah, R. A., Mirdanies, M., Santoso, A., Nugraha, A. S., Muqorrobin, A., ... Rijanto, E. (2012). Perancangan dan Pengujian Awal Kendali Motor DC Brushless Untuk Independent 4-Wheel Drive Platform Robot Rev-11. Mechatronics, Electrical Power, and Vehicular Technology, 2(2), 85-94. https://doi.org/10.14203/j.mev.2011.v2.85-94

Shanmugasundram, R., Zakariah, K. M., \& Yadaiah, N. (2014). Implementation and Performance Analysis of Digital Controllers for Brushless DC Motor Drives. Ieee Transactions on Mechatronics, 19(1), 213-224.

Syifa, F. T., \& Firmansyah, E. (2015). Pengendalian Motor DC Tanpa Sikat Sederhana dengan DSC 16-bit pada Aplikasi EDF. Jnteti, 4(4), 4-8.

Tibor, B., Fedak, V., \& Duurovský, F. (2011). Modeling and simulation of the BLDC motor in MATLAB GUI. Proceedings - ISIE 2011: 2011 IEEE International Symposium on Industrial Electronics, 1403-1407. https://doi.org/10.1109/ISIE.2011.5984365

Varatharaju, V. M., Mathur, B. L., \& Udhyakumar, K. (2010). Speed control of PMBLDC motor using MATLAB/simulink and effects of load and inertia changes. ICMET $2010-2010$ International Conference on Mechanical and Electrical Technology, Proceedings, (Icmet), 543-548. https://doi.org/10.1109/ICMET.2010.5598420 
Wahono, T., \& Sutikno, T. (2016). Skema Pengendali Motor BLDC Tanpa Sensor Posisi Rotor dengan Metode Deteksi Back EMF Berbasis Mikrokontroler Arduino. IImu Teknik Elektro Komputer Dan Informatika, 2(2), 22-29.

Waluyo, Fitriansyah, A., \& Syahrial. (2013). Analisis Penalaan Kontrol PID pada Simulasi Kendali Kecepatan Putaran Motor DC Berbeban menggunakan Metode Heuristik. Jurnal Elkomika, 1(2), 79-92.

Yulianta, A. D., Hadi, S. P., \& Suharyanto. (2015). Pengendalian Kecepatan Motor Brushless dc Menggunakan Metode Logika Fuzzy. Jurnal Sains, Teknologi Dan Industri, 8(1), 1-9. 